\title{
GUIA PEDAGÓGICO: CONSTRUÇÃO DE HISTÓRIAS EM QUADRINHOS PARA O ENSINO DO TEMA EVOLUÇÃO DOS MODELOS ATÔMICOS
}

\author{
Josineide Alves da Silva \\ Juliana Rocha Rodrigues Barcellos \\ Lidiane Aparecida de Almeida
}

"Brincar não é perder tempo, é ganhá-lo. É triste ter meninos sem escola, mas mais triste é vê-los enfileirados em salas sem ar, com exercícios estéreis, sem valor para a formação humana."

Carlos Drumond de Andrade

\section{Introdução}

Nas últimas décadas, publicações em revistas especializadas em Ensino de Química têm alertado para o desinteresse crescente dos estudantes pelas ciências básicas ensinadas nas escolas. Tal fato tem sido associado a um método de ensino puramente expositivo e na transmissão de conhecimento centralizada no professor. Em uma época de tantos estímulos externos - como a internet e os dispositivos eletrônicos - atrair a atenção dos 
jovens para a Ciência tem sido um desafio. No entanto, grande parte desse público aprecia o gênero Histórias em Quadrinhos (HQs) e dedica tempo a esse tipo de leitura. Evidência disso é o número de publicações do gênero, disponíveis tanto em bancas quanto na internet (RODRIGUES e QUADROS, 2018; ESTEVÃO, 2017). Portanto, a proposta deste trabalho para minimizar a mecanicidade do ensino é o desenvolvimento de Histórias em Quadrinhos para o ensino do tema Evolução dos Modelos Atômicos nas aulas de Química.

Desta forma, contrapondo a um ensino descontextualizado que, por vezes, é comum no ensino de Química, apresentamos um guia pedagógico constituído por recursos didáticos que buscam resgatar a memória afetiva e o lúdico. De acordo com Freitas e Aguiar (2012), o lúdico busca a criatividade e propõe que o estudante explore fatos, situações e ideias, permitindo, inclusive, o foco interdisciplinar. Além disso, a inclusão desse tipo de material na sala de aula é recebida com entusiasmo por parte dos estudantes (BARI, 2008).

Nas escolas brasileiras costuma ser no $9^{\circ}$ ano do Ensino Fundamental que o aluno tem seu primeiro contato com o discurso escolar característico da Química. É, portanto, uma oportunidade de valorizar uma metodologia ativa, onde o sujeito é convidado a buscar mais conhecimentos, exercendo sua autonomia, sempre mediado pelo professor. As trocas podem ser incentivadas por tra- 
balhos em grupo, onde a negociação, o diálogo e apropriação de conhecimentos são feitos coletivamente (MACHADO, 1999).

Este guia pedagógico é um produto educacional obtido a partir de pesquisas realizadas durante o curso de Mestrado Profissional do Programa de Pós Graduação em Ensino em Educação Básica (PPGEB - UERJ). Tal produto consta de atividades em que os alunos são incentivados a buscar como o conhecimento científico foi construído histórica e socialmente em relação ao conceito de Átomo. Ao se apropriarem deste conhecimento, os estudantes irão construir Histórias em Quadrinhos, aproximando os conceitos abstratos a uma linguagem com aspectos culturais de cada um dos grupos de aluno. Neste processo valoriza-se o desenvolvimento do discurso químico coletivo, mais importante que o armazenamento do conteúdo, onde apenas a voz do professor é destacada (MORAES e RAMOS, 2010).

Portanto, este produto educacional propõe uma nova forma de abordar o conteúdo "Evolução dos Modelos Atômicos" e possibilita que estejam reunidos, na sala de aula, a experiência docente, os conhecimentos prévios dos alunos, um material potencialmente significativo e que estimula a participação ativa dos estudantes na busca de mais informações sobre o conhecimento científico. 


\section{A aprendizagem significativa}

A Teoria da Aprendizagem Significativa, proposta por David Ausubel (2003), busca entender como é a aprendizagem no contexto escolar e destaca o conhecimento que o aluno traz, ou seja, é uma teoria que se ocupa dos processos de ensino-aprendizagem dos conhecimentos científicos a partir dos conceitos do dia a dia dos alunos. Para Ausubel a aprendizagem só poderia acontecer de maneira concreta quando passasse a ter um significado para o sujeito. "O mais importante fator isolado que influencia a aprendizagem é o que o aprendiz já sabe. Determine isso e ensine-o de acordo" (AUSUBEL, 2003 apud MOREIRA, 2001).

Para Ausubel a interação entre os conhecimentos novos e os já existentes não ocorre literalmente e tampouco com qualquer conhecimento prévio. Para que a aprendizagem significativa ocorra é necessário um conhecimento específico e relevante presente na estrutura cognitiva do sujeito que o autor denomina ideia âncora ou subsunçor (MOREIRA, 2001).

A aprendizagem significativa é um processo dinâmico e está relacionada à organização cognitiva do aluno no processo de aprender. Ausubel propõe uma aprendizagem por descoberta, pois o fato de o conhecimento estar inacabado pode de ser um estímulo para que o aluno se interesse em descobrir o conhecimento antes do 
processo de assimilação (AUSUBEL, NOVAK, HANESIAN, 1980). Portanto, a teoria da aprendizagem significativa explica o conhecimento como atos de construção do sujeito, que dependendo das condições de cada um em compreender, elaborar, refletir, transformar e relacionar, podem ser utilizados de forma mais completa os estímulos externos e as relações interpessoais, ou seja, é o indivíduo que atribui significado ao mundo ao seu redor ao refletir e compreender os conhecimentos adquiridos. Segundo Moreira (2001), os significados obtidos por cada aluno são únicos, pois a estrutura cognitiva é particular.

Algumas condições são necessárias para que a aprendizagem significativa aconteça. Segundo Ausubel, Novak e Hanesian (1980) a existência de conceitos subsunçores servem de âncora para um novo conhecimento, com o objetivo de ter um significado para o indivíduo. Para Moreira (2001) uma outra condição é a vontade que o aluno tem em aprender, pois a aprendizagem acontece em cada sujeito na sua relação com o objeto do conhecimento, levando em consideração o contexto social e cultural e a interação sujeito-professor. Outra condição necessária está atrelada ao potencial significativo do conteúdo a ser trabalhado, pois este não pode ser um objeto vazio de significado social. Além disso, o conteúdo precisa seguir uma lógica, partindo de conhecimentos mais amplos para os mais específicos. Portanto, de acordo com essas condições Ausubel se preocupava com o caminho 
do processo de aquisição, retenção e transferência de significados, além da natureza do material da aprendizagem (LEMOS, 2002).

O tema evolução dos modelos atômicos no ensino de Química

Ainda hoje não são raras as discussões acerca do currículo que é praticado nas escolas de forma desconectada do cotidiano dos alunos. E isso também ocorre com o currículo da disciplina de Química, que geralmente é determinado por setores externos à escola. No entanto, atualmente, o que se deseja é que o aluno utilize os conhecimentos científicos para despertar uma cidadania em prol de uma qualidade de vida mais favorável ao ser humano. Para isso, é necessário que o estudante compreenda que o conhecimento em Ciências da Natureza se trata de um processo em construção. "A Ciência pode ser considerada uma linguagem construída pelos homens e mulheres para explicar nosso mundo natural" (CHASSOT, 2008, p.63). Além disso, a Ciência deve ser vista como um conhecimento limitado e imperfeito.

Ciência é uma das mais extraordinárias criações do homem, que lhe confere, ao mesmo tempo, poderes e satisfação intelectual, até pela estética que suas explicações lhe proporcionam. No entanto, ela não é lugar de certezas e [...] nossos conhecimentos ci- 
entíficos são necessariamente parciais e relativos (CHASSOT, 2008a, p. 113).

O ensino de Química, em sua maioria, é descontextualizado, centrado na figura docente, abstrato e extremamente difícil para os estudantes. Portanto, esse processo de ensino-aprendizagem é um grande desafio para as comunidades escolares, visto que esse ensino tradicional faz com que os alunos que chegam ao $9^{0}$ ano do Ensino Fundamental tenham uma visão distorcida desta Ciência, conduzindo a um desinteresse nos alunos (ROCHA; VASCONCELOS, 2016).

Mesmo com a tentativa de contextualização do ensino é ineficiente apenas mencionar fatos do cotidiano como uma forma moderna de ensinar. Sendo assim, Santos e Schnetzler apontam que:

O ensino para a cidadania não se restringe ao fornecimento de informações essenciais ao cidadão, tarefa necessária, mas não suficiente. Aliado à informação química, o ensino aqui defendido precisa propiciar condições para o desenvolvimento de habilidades, o que não se dá por meio simplesmente do conhecimento, mas de estratégias de ensino muito bem estruturadas e organizadas (SANTOS; SCHNETZLER, 2000, p.113).

O tema Evolução dos Modelos Atômicos é um componente curricular do $9^{\circ}$ ano do Ensino Fundamental 
da disciplina de Ciências ou, em algumas escolas, de Química. É um tema pouco abordado em avaliações externas e ao longo dos anos este assunto tem sido tratado muito rapidamente nas escolas, com uma preocupação apenas em citar o nome dos cientistas e suas ideias sobre o Átomo. No entanto, essa temática pede um planejamento cuidadoso, pois exige uma compreensão a nível microscópico, já que envolve estruturas que não podem ser visualizadas. Dessa forma, a dificuldade começa ao tentar estabelecer o conceito de modelo científico e o grande desafio é mostrar que o modelo atômico, por exemplo, é um processo dinâmico e sujeito a mudanças.

Torna-se fundamental uma discussão em cada um dos modelos atômicos considerando uma abordagem histórica enfatizando que à medida que novos conhecimentos eram adquiridos, o modelo anterior era modificado e essa abordagem está em consonância com a recomendação da Base Nacional Comum Curricular (BNCC) e esse tema tem como habilidade: "Identificar modelos que descrevem a estrutura da matéria e reconhecer sua evolução histórica” (BRASIL, 2017). Portanto, com este guia pedagógico, o professor poderá proporcionar aos seus alunos um estudo de como os cientistas elaboravam teorias para explicar fenômenos da natureza e com isso, os estudantes poderão aplicar este modelo a uma situação corriqueira, relacionando o conhecimento ao contexto sócio-histórico-cultural, assim como indicado na BNCC. 
O uso das Histórias em Quadrinhos (HQs) no processo ensino-aprendizagem

O uso das HQs no processo educacional é reconhecido tanto pela Lei de Diretrizes e Bases (LDB) quanto pelos Parâmetros Curriculares Nacionais (PCNs). Apesar de existirem diversos trabalhos envolvendo HQs o compartilhamento destas experiências ainda é muito pequeno. Além disso, há muita dificuldade em relacionar o lúdico das HQs ao ensino (AQUINO e colaboradores, 2015), pois a origem das HQs está ligada ao entretenimento e, portanto, é um grande desafio para o professor considerar as HQs um recurso pedagógico (SANTOS; SILVA; ACIOLI, 2012).

Segundo Santos e Pereira (2013), as HQs podem incentivar a leitura para aqueles alunos que não têm interesse em ler outro gênero. Além disso, Vergueiro (2015) afirma que o emprego das HQs permite que os alunos se abram para a leitura, favorecendo a concentração em outras leituras destinadas ao estudo.

Os professores da Educação Básica lidam com um currículo extenso, condições inadequadas de trabalho, falta de tempo para preparar as atividades lúdicas, além de muitos docentes entenderem que tais atividades são pouco eficazes e que geram indisciplina, e dessa forma, não se sentem motivados para usarem recursos lúdicos (BARROSO, 2008). Mesmo que essas razões sejam legí- 
timas, é válido incluir as HQs nas aulas, pois estas promovem um envolvimento emocional e pode motivar o aluno a vencer dificuldades (MODESTO; RUBIO, 2014).

Portanto, esse guia pedagógico propõe a inserção das HQs no ensino do tema Evolução dos Modelos Atômicos, de modo que o estudante resgaste em sua memória afetiva o componente lúdico desse recurso.

\section{Propostas de atividades para o uso das HQs no en- sino do tema Evolução dos Modelos Atômicos}

Nesta seção são apresentadas propostas de como utilizar as HQs ao trabalhar com o tema Evolução dos Modelos Atômicos. As atividades permitem que os alunos sejam inseridos no contexto histórico-social-político de cada nova ideia que surgiu acerca do tema Átomo. Estas atividades incluem a investigação sobre a existência de ideias âncoras (subsunçores) relacionadas ao conceito de Átomo, passando pela definição do que é um modelo científico até chegar na construção dos Modelos Atômicos pelos cientistas a partir de perguntas norteadoras que podem ser disponibilizadas aos alunos para que estes pesquisem o tema em questão, incentivando, dessa maneira, a aprendizagem por descoberta. Após as atividades de aprofundamento no tema, há a sugestão de uma atividade para a construção das HQs sobre a Evolução dos Modelos Atômicos. Além disso, as atividades aqui pro- 
postas podem ser aplicadas a outros temas, colaborando para a qualidade no ensino de Química.

- Primeira atividade: Construção do mapa mental coletivo

De acordo com a Teoria da Aprendizagem Significativa, as concepções iniciais dos alunos devem servir de base para a aprendizagem de novos conceitos. Portanto, a primeira atividade proposta é a confecção de um mapa mental acerca do tema Átomo com a turma. Um mapa mental pode ser entendido como "uma ferramenta pedagógica de organização de ideias por meio de palavraschave, cores e imagens em uma estrutura que se irradia a partir de um centro" (BUZAN, 2009 apud GALANTE, 2014). A intenção é de uma construção partilhada por todos os alunos disposta no quadro branco, em um esquema como apresentado na Figura 1. Tempo necessário para construção do mapa mental: um tempo de aula.

Figura 1: Esquema de mapa mental

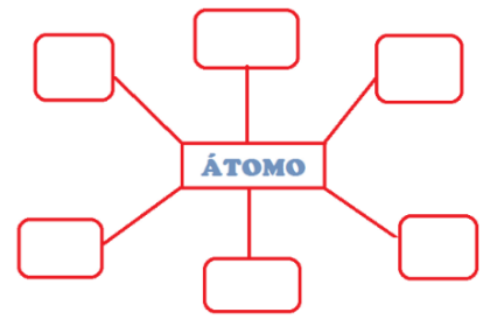

Fonte: As autoras, 2020. 
- Segunda atividade: Dinâmica para a apresentação do conceito de modelo científico

Devido à importância do conceito de modelo sugere-se uma dinâmica onde a intenção é elucidar e discutir o conceito de modelo. Nessa dinâmica é necessário que os alunos sejam divididos em grupos e cada grupo receberá uma caixa fechada contendo três objetos do mundo escolar. Os alunos podem manusear a caixa e desenhar possíveis formas para cada um dos três objetos, sem que a caixa seja aberta. Os objetos de cada grupo podem ser iguais ou diferentes, mas é importante que todos sejam do contexto escolar. Após os alunos desenharem os objetos, sugere-se uma discussão sobre a construção do conhecimento a partir de modelos. O objetivo dessa atividade é despertar a ideia de que da mesma maneira que os alunos, cada cientista propôs um modelo de átomo que conseguia "enxergar" no seu tempo histórico. Tempo necessário para a realização da atividade em sala de aula: um tempo de aula.

- Terceira atividade: Sorteio dos temas para cada grupo

Após a discussão acerca do conceito de modelo atômico recomenda-se dividir a turma em quatro grupos 
e promover um sorteio dos seguintes temas para os grupos:

$\checkmark$ Tema 1: Modelo atômico de John Dalton

$\checkmark$ Tema 2: Modelo atômico de Thompson

$\checkmark$ Tema 3: Modelo atômico de Rutherford

$\checkmark$ Tema 4: Modelo atômico de Rutherford-Bohr

Como um dos objetivos do trabalho das HQs é que os alunos entendam a importância do contexto histórico (Figura 2) no desenvolvimento dos modelos científicos e da própria Ciência, após o sorteio dos temas, algumas perguntas norteadoras podem ser propostas para que os grupos pesquisem. Com essa ação de pesquisa, os alunos poderão ser estimulados a descobrir o conhecimento antes do processo de assimilação e isso favorecerá a aprendizagem significativa. As questões problematizadoras ou investigativas proporcionam um embasamento teórico aos estudantes sobre cada um dos modelos. 


\section{Perguntas norteadoras:}

Figura 2: Onde estamos na História?

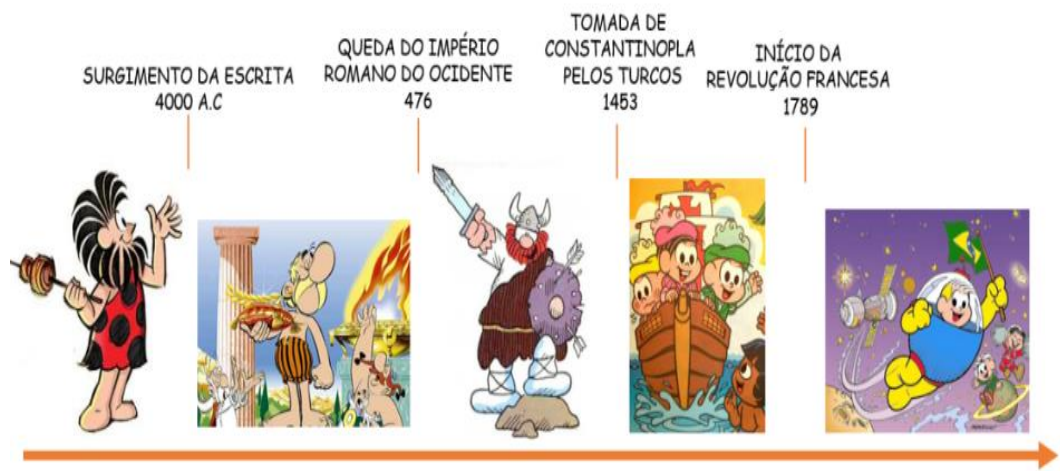

PRÉ-HISTÓRIA IDADE ANTIGA IDADE MÉDIA IDADE MODERNA

ERA CRISTÃ

Fonte: As autoras, 2020.

Grupo I. Modelo Atômico de Dalton

Questões importantes:

1. Qual o contexto histórico do desenvolvimento do modelo atômico de Dalton (1808)? Como era o homem no início do século XIX? E a civilização contemporânea? 
2. Qual a contribuição da Alquimia para o desenvolvimento do modelo atômico de Dalton?

3. Qual a importância do modelo atômico de Leucipo e Demócrito para o desenvolvimento do modelo atômico de Dalton?

4. O que foi o modelo atômico de Dalton? Como é conhecido? Quais as suas características? Quando e onde surgiu? Quando foi questionado? Por quê?

5. Qual a importância do desenvolvimento do modelo atômico de Dalton para o desenvolvimento da Ciência?

Grupo II. Modelo Atômico de Thompson

Questões importantes:

1. Qual o contexto histórico do desenvolvimento do modelo atômico de Thompson?

2. Qual foi a importância da descoberta do elétron (descreva a experiência) para o desenvolvimento do modelo atômico de Thompson? 
3. O que foi o modelo atômico de Thompson? Como é conhecido? Quais as suas características? Quando e onde surgiu? Quando foi questionado? Por quê?

4. O que há de comum entre o modelo atômico de Dalton e o modelo atômico de Thompson?

5. Qual a importância do desenvolvimento do modelo atômico de Thompson para o desenvolvimento da Ciência e para a civilização?

Grupo III. Modelo Atômico de Rutherford

Questões importantes:

1. Qual o contexto histórico do desenvolvimento do modelo atômico de Rutherford (1911)? Como era o homem no início do século XX? E a civilização contemporânea?

2. Qual a importância da descoberta da radioatividade (1896) e a do próton (1904) para o desenvolvimento do modelo atômico de Rutherford?

3. Como ocorreu a experiência com uma lâmina de ouro (1910)? Quais as observações de Rutherford? Qual importância dessa experiência? 
4. O que foi o modelo atômico de Rutherford? Como é conhecido? Quais as suas características? Quando e onde surgiu? Há limitação no modelo atômico de Rutherford? Comente.

5. Qual a importância do desenvolvimento do modelo atômico de Rutherford para o desenvolvimento da Ciência e para a civilização?

Grupo IV. Modelo Atômico de Rutherford-Bohr

Questões importantes:

1. Qual o contexto histórico do desenvolvimento do modelo atômico de Rutherford-Bohr (1913)? Como era o homem no início do século XX? E a civilização contemporânea?

2. Como ocorreu o desenvolvimento do modelo atômico de Rutherford-Bohr?

3. Qual a contribuição do modelo atômico de Rutherford para o desenvolvimento do modelo atômico de Rutherford-Bohr?

4. O que foi o modelo atômico de Rutherford-Bohr? Como é conhecido? Quais as suas características? 
Quando e onde surgiu? Quando foi questionado? Qual foi sua principal limitação?

5. Qual a importância do modelo atômico de Rutherford-Bohr para o desenvolvimento da Ciência e da civilização?

\section{- Quarta atividade: Confecção das HQs}

Após a pesquisa sobre cada modelo atômico a partir das perguntas norteadoras, sugere-se disponibilizar um tempo para que os grupos tirem suas dúvidas e comecem a confeccionar um roteiro com definição de cenário e de personagens.

Durante atividade pode haver uma preocupação inicial dos alunos quanto à estética do trabalho. Portanto, é fundamental que o professor explique que este não é o objetivo da atividade. O importante é deixar a imaginação fluir.

Nessa etapa de construção das HQs os alunos podem construir suas histórias e desenhar seus personagens e cenários à mão livre ou a partir de recursos e plataformas disponíveis na internet. Há, sites gratuitos com uma série de recursos que permitem a escolha cenários, per- 
sonagens e incentivam a produção autoral de histórias ${ }^{1}$. Tempo necessário para a realização da atividade: 15 dias.

- Quinta atividade: Apresentação das HQs

Com o objetivo de divulgar os conhecimentos descobertos por cada grupo de alunos, sugere-se uma apresentação das HQs para a turma, ou caso a escola tenha mais de uma turma de $9^{\circ}$ ano ou $1^{\circ}$ ano do Ensino Médio é possível fazer trocas expositivas entre as turmas. O tempo de cada apresentação pode ser combinado entre o professor e a turma. Além das apresentações, recomenda-se fazer cópias das HQs e na aula seguinte distribuílas aos grupos, possibilitando que todos tenham acesso aos trabalhos desenvolvidos. Além disso, a socialização dos HQs permite que o professor verifique quais conceitos precisam ser revistos.

- Sexta atividade: Construção do mapa mental pósHQs

Após a socialização das HQs recomenda-se fazer um novo mapa mental partindo novamente da palavra

${ }^{1}$ Um destes sites pode ser encontrado em: http://porvir.org/7ferramentas-para-criar-historias-em-quadrinhos-os-alunos/, ou pela plataforma Canva (www.canva.com). 
Átomo. O objetivo da construção desse novo mapa mental é fazer com que os alunos percebam que novos conhecimentos foram construídos sobre o tema a partir da confecção das HQs. Além disso, sugere-se que seja realizada uma comparação entre o mapa mental confeccionado no início com o construído no final para consolidar, corrigir ou aperfeiçoar alguns conceitos.

\section{Uma História em Quadrinhos sobre o modelo atômi- co de Rutherford}

A seguir há uma proposta de uma HQ produzida pelas autoras para apresentar o modelo atômico de $\mathrm{Ru}$ therford (Figura 3). É uma outra forma de trabalhar, onde o professor apresenta uma história pronta, caso não tenha disponibilidade de tempo para realizar todas as atividades propostas neste guia. Com isso, o professor pode incentivar o aluno a desenvolver uma outra HQ à mão livre ou a partir de recursos disponíveis na internet, de outro modelo atômico ou de outro conteúdo. Vale ressaltar que a HQ apresentada é uma sugestão de um material lúdico para o professor trabalhar o modelo atômico de Rutherford, partindo do modelo atômico de Thompson. Ao final da história proposta, um dos personagens deixa uma pergunta que pode servir de incentivo para que os alunos pesquisem sobre o problema apresentado, levando-os aos postulados de Bohr. Desta maneira, é pos- 
sível despertar no estudante a ideia de que o conhecimento é construído histórico e socialmente .

Figura 3: HQ produzida sobre o modelo atômico de Rutherford

\section{QUIMICA EM QUADRINHOS}

CAPÍTULO 1: O MODELO ATÔMICO DE THOMPSON

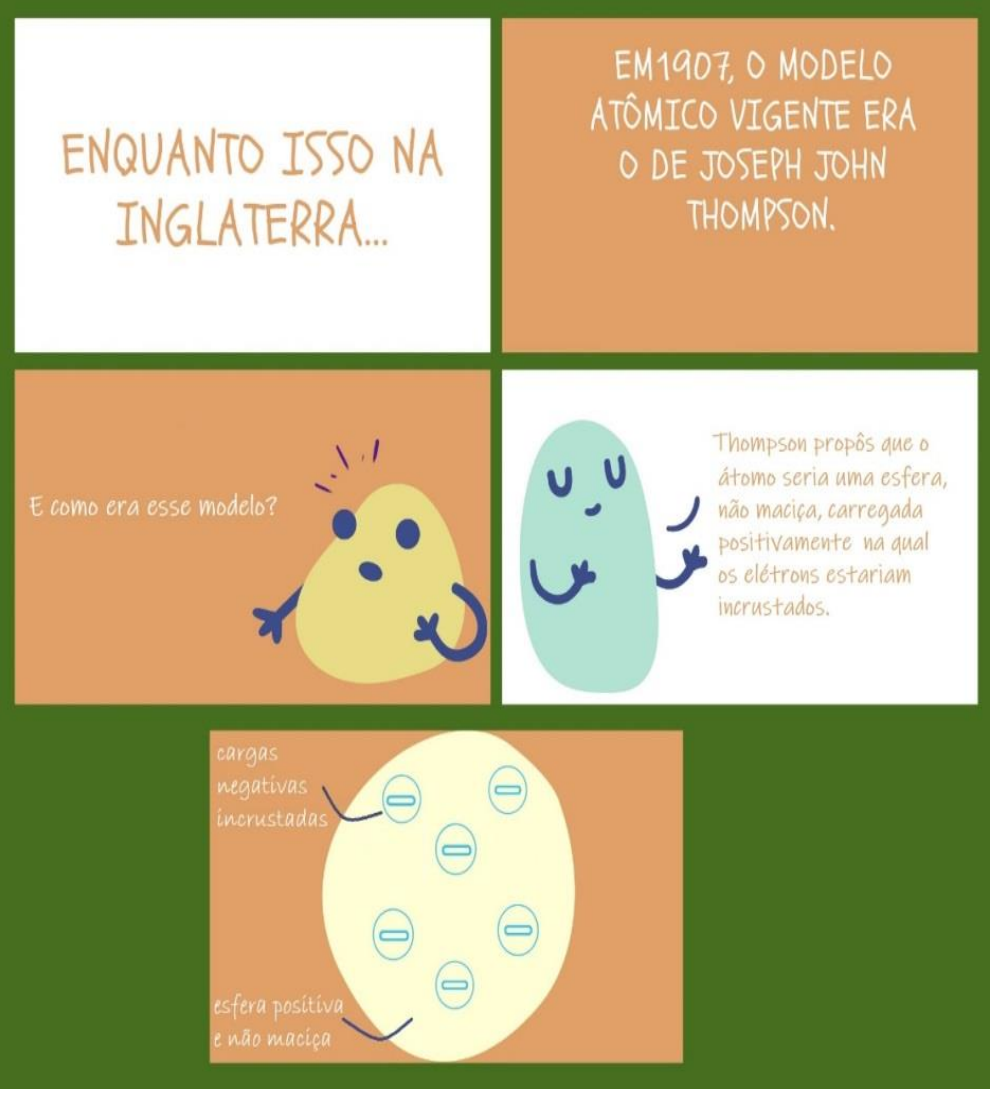



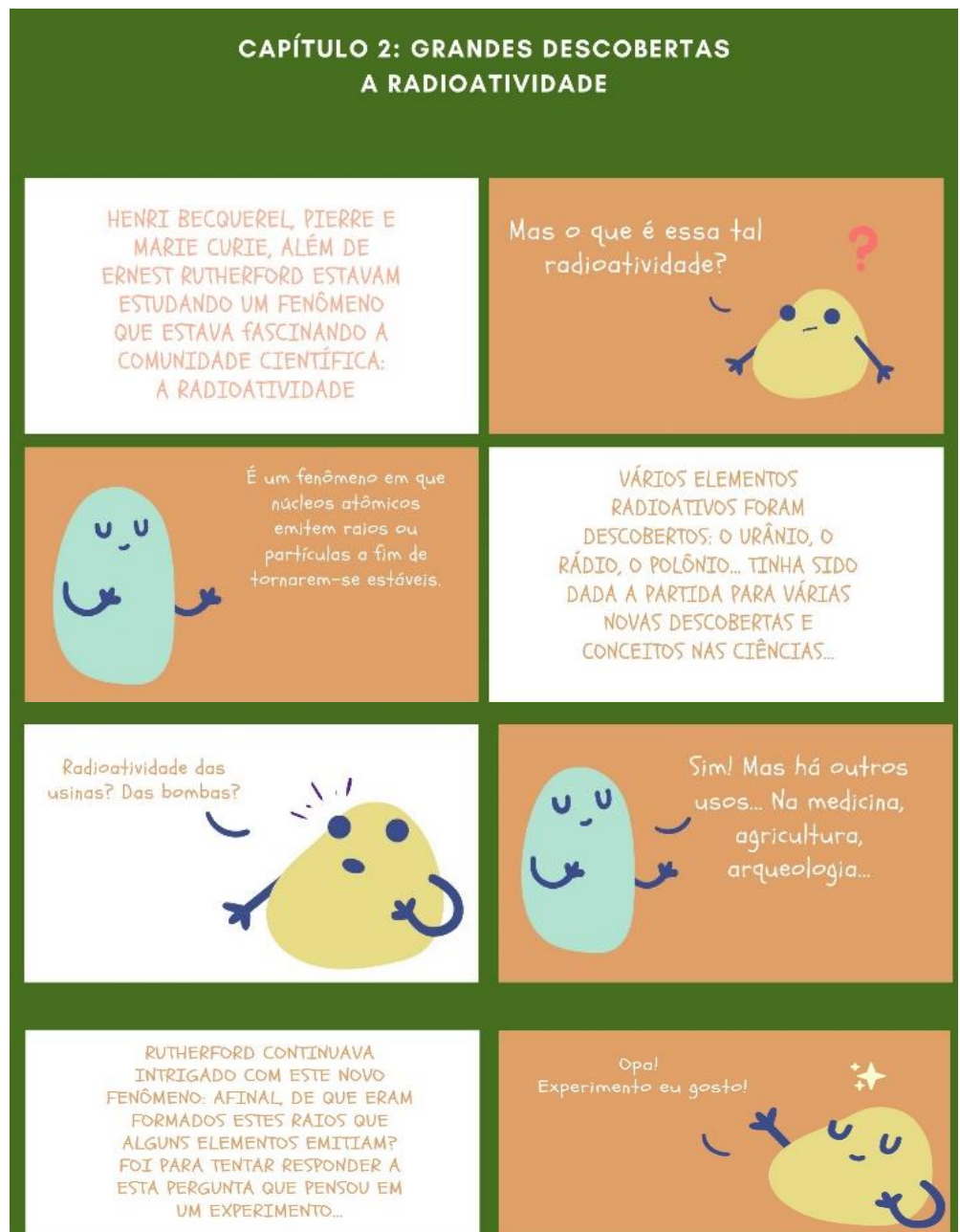

RUTHERFORD CONTINUAVA INTRIGADO COM ESTE NOVO RA TENTAR RESPONDER A UM EXPERTMENTO
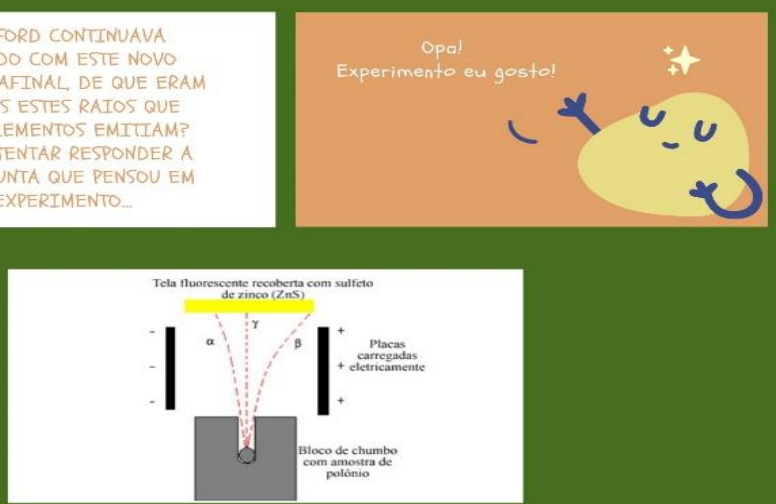


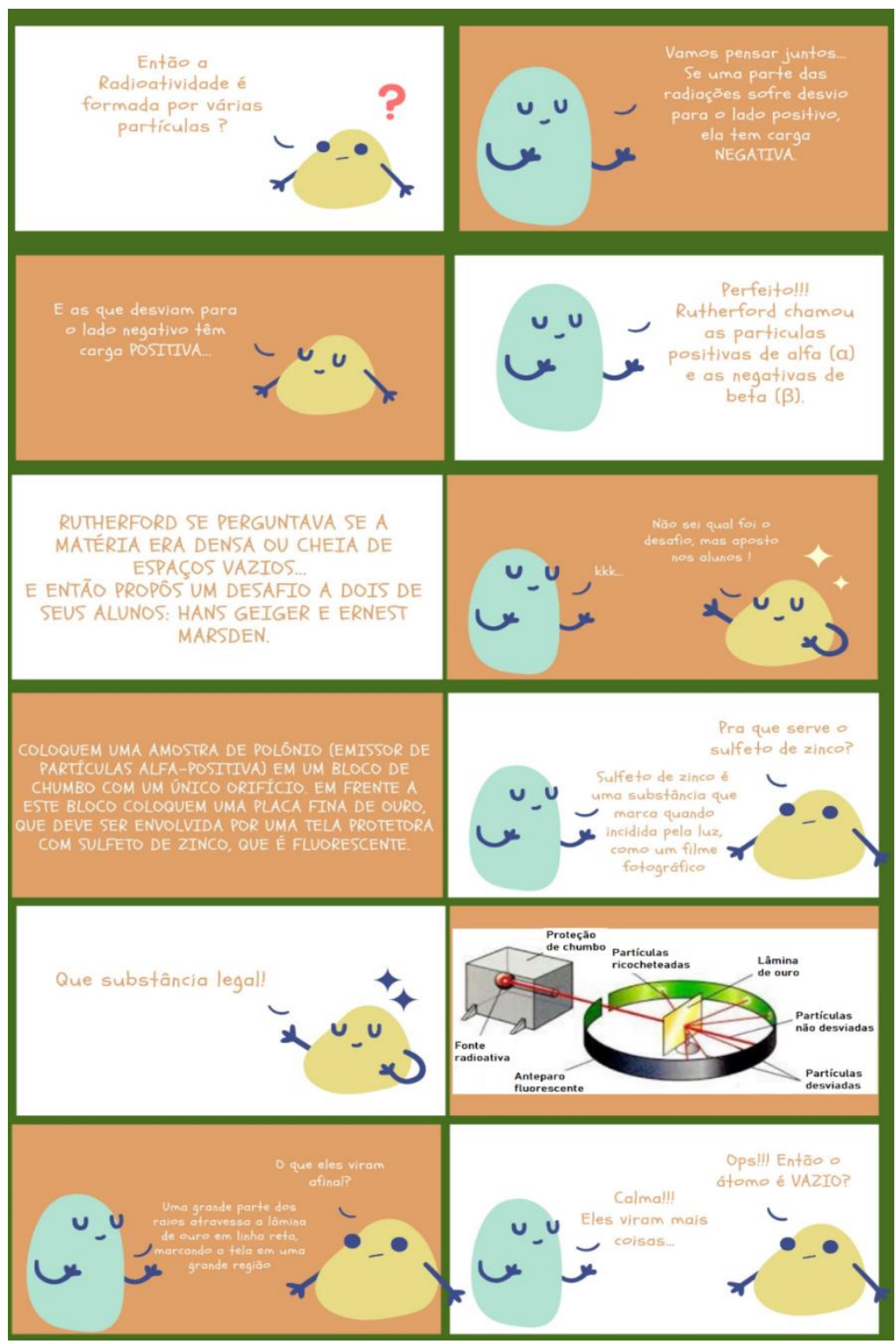




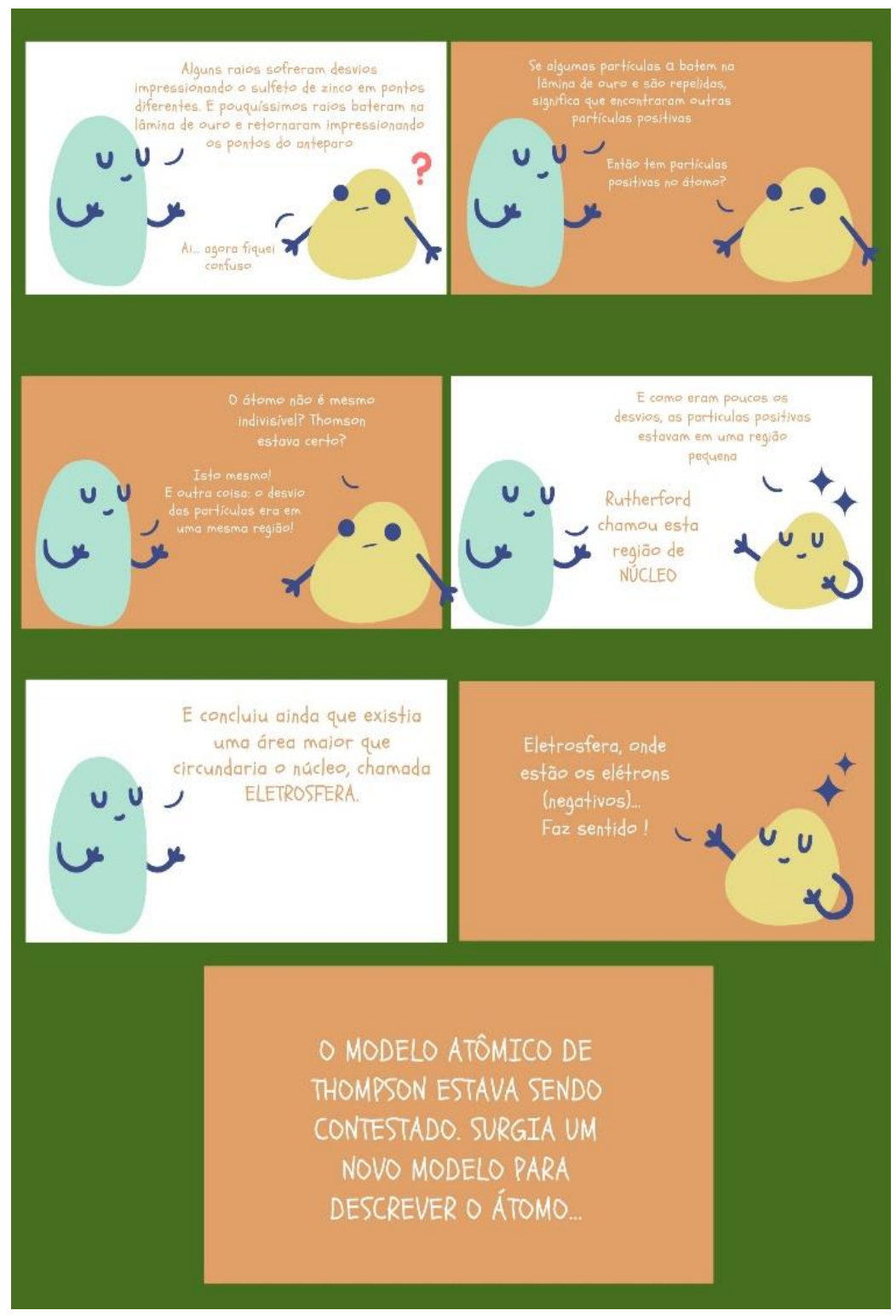




\section{CAPÍTULO 3: O MODELO PLANETÁRIO}

RUTHERFORD TROUXE DE

THOMSON A IDEIA DA EXISTÊNCIA DOS ELÉTRONS (CARGA NEGATIVA) E CRIA A IDEIA DE CARGAS POSITIVAS
EM 1909, FOI PUBLICADO UM ARTIGO ESCRTTO POR GERGER E MARSEN RELATANDO O ESPALHAMENTO DAS PARTICULAS ALFA AC BOMBARDEAR UMA LAMINA DE OURO
EM 19II, RUTHERFORD

ESCREVEU UM ARTIGO ANALISANDO O EXPERIMENTO DE GERGER E MARSDEN E DANDO UM TRATAMENTO MATEMÁTICO A ELE
Rutherford propôs um modelo comparado com o

$\checkmark \mathbf{U}$ sistema solar, em que os elétrons seriam os planetas e o núcleo, o sol.
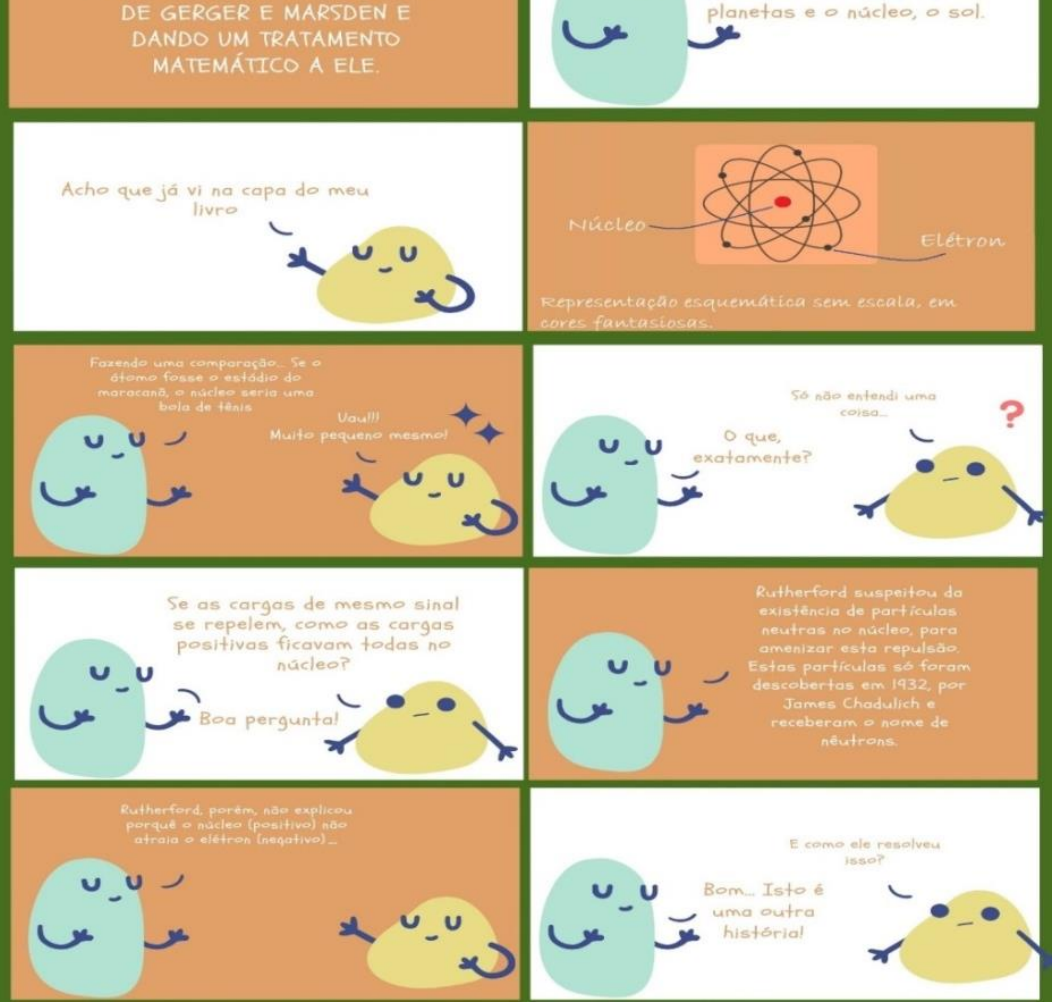

Fonte: As autoras, 2020. 


\section{Conclusões}

Esse guia pedagógico busca integrar, no processo de construção de Histórias em Quadrinhos, uma metodologia ativa, onde cada grupo de estudantes é motivado a buscar os conhecimentos científicos, levando, dessa forma, à aprendizagem significativa.

As atividades são propostas para os alunos a partir do $9^{\circ}$ ano do Ensino Fundamental, com o uso de uma linguagem conhecida pelos estudantes, resgatando a memória do lúdico presente na infância. Além disso, as atividades partem das premissas essenciais da Teoria da Aprendizagem Significativa que levam em consideração a vontade do aluno de aprender e a valorização de seus conhecimentos prévios.

As etapas foram planejadas de modo que a construção das histórias possibilite uma aprendizagem significativa, pois a identificação dos conceitos prévios (subsunçores) dos alunos a respeito do conceito Átomo podem ser obtidos a partir do mapa mental inicial. Além disso, a construção coletiva do conceito de modelo e a sua analogia com o modelo científico, as perguntas norteadoras que vão direcionar os alunos à pesquisa, a socialização das Histórias em Quadrinhos e a construção do mapa mental final permitirão que o professor identifique os novos conceitos incorporados e quais precisam ser revistos. 
$\mathrm{O}$ uso da imagem-texto permite resgatar as memórias dos alunos, o que pode despertar uma vontade de trabalhar, dialogar, refletir e questionar os novos conceitos, o que os tornam significativos.

Portanto, o emprego de Histórias em Quadrinhos pode contribuir com o processo ensino-aprendizagem de Química, pois apresenta uma linguagem mais acessível aos alunos, os quais podem usar suas experiências cotidianas para interpretar os assuntos, tornando mais significativo um conhecimento abstrato. Sendo assim, esse guia pedagógico incentiva a produção de Histórias em Quadrinhos que darão voz aos alunos, que poderão dividir dúvidas, divulgar experiências e conhecimentos científicos que eles próprios pesquisaram.

Esse guia é um produto para o professor que enfrenta dificuldades em encontrar uma atividade que possibilita a participação ativa do aluno, estimulando-o a construir um pensamento químico necessário ao desenvolvimento de conteúdos futuros.

\section{Referências}

AQUINO, F.; FIORUCCI, A.; FILHO-BENEDETTI, E.; BENEDETTI, L. Elaboração, Aplicação e Avaliação de uma HQ Sobre Conteúdo de História dos Modelos Atômicos para o Ensino de Química. Orbital The Electronic Journal of Chemistry, 
Campo Grande, v. 7, n.1, p. 53-58, 2015. Disponível em: $<$ www.researchgate.net $>$. Acesso em: 28 out. 2020.

AUSUBEL, D. P. Aquisição e retenção de conhecimentos: Uma perspectiva cognitiva. Lisboa: Plátano, 2003.

AUSUBEL, D. P.; NOVAK, J. D.; HANESIAN, H. Psicologia Educacional. Rio de Janeiro: Interamericana, 1980.

BARI, V. A. O potencial das histórias em quadrinhos na formação de leitores: busca de um contraponto entre panoramas culturais brasileiro e europeu. 2008. 250f. Tese (Doutorado em Ciência da Informação) - Escola de Comunicação e Artes, Universidade de São Paulo, 2008.

BARROSO, M. F. Formação de professores de Ciências e Matemática para uma educação de qualidade. GT - EDUCAÇÃO DA SBPC; Rio de Janeiro: LIMC, 2008.

BRASIL, Ministério da Educação. Base nacional Comum Curricular. Ministério da Educação, Brasília, DF: MEC, 2017. Disponível

em

<http://basenacionalcomum.mec.gov.br/imagens/BNCCpubli cacao.pdf. > Acesso em: 10 set. 2020.

CHASSOT, A. Saberes primevos fazendo-se saberes escolares. Sete escritos sobre educação e ciência. São Paulo: Cortez, 2008.

ESTEVÃO, A. P. S. da S. História em Quadrinhos no ensino de Química como estratégia didática para abordagem do tema "lixo eletrônico". 2017. 225f. Tese (Doutorado em Ensino em Biociências e Saúde) - Instituto Oswaldo Cruz, 2017. 
FREITAS, M. S.; AGUIAR, G. P. Educação e ludicidade na primeira fase do ensino fundamental. Interdisciplinar: Revista Eletrônica da Univar, n. 7, p. 21-25, 2012.

GALANTE, C. E. da S. O uso de mapas conceituais e mapas mentais como ferramentas pedagógicas no contexto educacional do ensino superior. Saber, v. 3, p. 1-28, 2014. Disponível em: $\quad<$ https://www.inesul.edu.br/revista/arquivos/arqidvol_28_1389979097.pdf >. Acesso em 02 nov. 2020.

LEMOS, A. Cibercultura. Porto Alegre: Sulina, 2002.

MACHADO, A. H. Aula de química: discurso e conhecimento. 1999. 149f. Tese (Doutorado em Educação) - Faculdade de Educação, Universidade Estadual de Campinas, Campinas, 1999.

Disponível em: <http://www.repositorio.unicamp.br/handle/REPOSIP/2532 79>. Acesso em: 29 out. 2020.

MODESTO, M. C.; RUBIO, J. de A. S. A importância da Ludicidade na construção do conhecimento. Revista Eletrônica saberes da Educação, São Roque, v. 5, n.1, p. 1-16, 2014. Disponível

em: <http://docs.uninove.br/arte/fac/publicacoes_pdf/educacao/ v5_n1_2014/Monica.pdf $>$. Acesso em: 28 ago. 2020.

MORAES, R.; RAMOS, M. G. O ensino de Química nos Anos Iniciais: Ampliando e Diversificando o Conhecimento de Mundo. In: BRASIL. Ministério da Educação Secretária de Educação Básica. Ciências: Ensino Fundamental (Coleção Explorando o ensino, v. 18). Brasília: MEC/SEB, 2010.

MOREIRA, M. A.; MASINI, E. F. S. Aprendizagem Significativa: a teoria de David Ausubel. São Paulo: Centauro, 2001. 
ROCHA, J. S.; VASCONCELOS, T. C. Dificuldades de aprendizagem no ensino de química: algumas reflexões. In XVIII Encontro Nacional de Ensino de Química (ENEQ) 2016. Disponível

em: <http://www.eneq2016.ufsc.br/anais/resumos/Ro145-2.pdf>. Acesso em: 12 mai. 2019.

RODRIGUES, A.; QUADROS, A. O envolvimento dos estudantes em aulas de Ciências por meio da linguagem narrativa das histórias em quadrinhos. Química Nova na Escola, São Paulo, v. 40, n.2, p. 126-137, 2018. Disponível em: <http://qnesc.sbq.org.br/online/qnesc40_2/10-CP-4017.pdf $>$. Acesso em: 31 out. 2020.

SANTOS, T. C. dos; PEREIRA, E. G. C. Histórias em quadrinhos como recurso pedagógico. Revista Práxis, v.5, n. 9, p. 5156, 2013.

SANTOS, V. J. da R. M.; SILVA, F. B.; ACIOLI, M. F. Produção de Histórias em Quadrinhos na abordagem interdisciplinar de Biologia e Química. Revista Renote: Novas Tecnologias na Educação, v. 10, n. 3, p. 1-8, 2012. Disponível em: <https://seer.ufrgs.br/renote/article/view/36467/23547>. Acesso em: 20 set. 2020.

SANTOS, W. L.; SCHNETZLER, R.. Química na Sociedade: projeto de um ensino de química em um contexto social (PEQS). Brasília: UnB, 2000.

VERGUEIRO, W. de C. S.; SANTOS, R. E. A Linguagem dos Quadrinhos. São Paulo: Criativo, 2015. 